Conference

Circuit

\title{
Finding common ground: Creating a future library
}

\author{
By Steve McKinzie
}

\section{Harvard University's first national library conference}

$\mathbf{T}$ ake Boston, birthplace of the nation's freedom, hub of the country's intellectual life, and a ciry of rich cultural diversity. Add Harvard University, gifted with one of the world's largest library collections and home to some of the profession's most creative librarians. Then combine it all with a clearheaded vision of how a national conference ought to be run and what you want it to accomplish.

The resulting mix, a potent formula for success by almost any standards, actually happened March 30-31 at the Charles Hotel in Cambridge, Massachusetts. Harvard University's first national library conference, "Finding Common Ground: Creating a Library of the Future without Diminishing the Library of the Past," gathered together more than 350 participants from the U.S. and abroad to explore the direction that libraries and information services will take into the next century. The conference set the parameters of the debate surrounding that future. It also provided a clear vision of the challenges facing librarians. Attendees may not have gotten all the answers to their questions but they came away with a lot of insight and perspective

The conference boasted two major speakers: Clifford Lynch (University of California-Berkeley) and Walt Crawford (RLG). It also pulled together nearly 60 contributed papers and approximately 30 demonstrated papers (Harvard's term for poster sessions)—papers, sessions, and panels that were on the whole extraordinarily provocative and superbly executed.

\section{Communities: A decline of geography}

Lynch set the stage for the conference in his keynote address by reminding his listeners that "libraries are social structures, organizations that relate to a certain mission and that exist within a social matrix." They also serve a community. That definition of a library isn't apt to change, Lynch insisted, but the notion of community can. There is a sort of growing "decline of geography," he added. Public libraries may serve international clients and Internet communities may span continents.

The task for libraries in this decline of geography isn't to function as gatekeepers for information, collections, or resources, but to provide value-added dimensions to data. People are going to need to understand what they are retrieving on the Web and what they're finding in a database. That means that libraries need to be instructing users and to be finding ways, however daunting the task may seem, of organizing and managing the resources of the Internet, just as they have traditionally indexed and cataloged book collections.

\section{Breaking myths of the digital age}

In his all-conference speech, "Uncommon Knowledge, Myth Breaking for the Future," Crawford spelled out what he thought were the major myths of the information age, falsehoods that needed to be exposed so that we can get on with the business of making the right choices about the future. His remarks echoed the themes of his and Michael Gorman's recently published Future Libraries: Dreams, Madness and Reality (ALA, 1995). With a common sense persuasiveness and cool-headed delivery, Crawford tried to restore a measure of balance and sanity to the dialogue about the changes that libraries are apt to see in the coming decades. For Crawford, the library of tomorrow won't be all digital. The scholar's universal workstation may never come, and the notion of the demise of print has been as exaggerated as the death of radio and river com- 


\section{For Crawford, the library of tomorrow won't be all}

digital. The scholar's universal workstation may never come, and ... the demise of print has been as exaggerated as the death of radio and river commerce.

merce, both booming businesses that are likely doing better than ever before.

\section{Direct access to information}

The conference also featured several all-conference panels. A publisher's panel included Heather Cameron (ABC-CLIO), Sonja Gustafson (Microsoft), Ann Hartman (consultant), and Patricia Glass Schuman (Neal-Schuman), and reflected on the historic synergism between publishing and libraries, speculated on possible joint ventures between the two, and discussed developments in electronic publishing.

Gustafson's experience at Microsoft served as a case study of how one major software producer or publisher took advantage of some of the Internet's potential. Over the last several years, Microsoft, with the aid of Gustafson and her library staff, began to use the Web as a kind of online library for both company clients and organizational personnel. The company maintained an extensive product support service for its customers, who downloaded information at will. Clients examined products and obtained specific online help. For its employees, Microsoft's Weh library provided data on company policy and benefits. It also created individualized homepages for anyone in the organization who wanted one. Gustafson insisted that she and her staff were in a sense using the Internet to disintermediate information, to eliminate that often unnecessary middle party in the access of data. The company disseminated information without tying up human resources. Clients and employees now had direct access to what they needed to know quicker and easier than ever before.

\section{Historic synergism}

Cameron and Hartman spoke more directly to specific questions surrounding publishers and publishing as they confronted the challenges of the information age. Cameron argued that the risks in publishing are perhaps greater than ever before-a dimension in the industry that almost everyone feels acutely. It is an era of sweeping technological change. User expecta- tions are high. Quality is very much in demand-so much in demand, Cameron added, that many classic reference works of the past wouldn't hegin to meet today's high publishing standards.

In response to that demand, Hartman suggested that libraries and publishers begin to explore ways in which they can encourage cooperation. The cooperation could manifest itself in a variety of ways. Libraries and publishers could even consider joint publishing ventures. She envisioned a cooperation that could be mutually beneficial.

Schuman agreed but suggested that libraries and publishers really need to restore some of their historic synergism before they venture too boldly into the future. She insisted that there has been simply too much miscommunication and competition between the groups in recent years. The two should work in tandem. The country needs healthy publishing and healthy libraries. Closer cooperation could ensure the vibrancy of both.

\section{A marriage made in heaven or hell}

Contributed papers ranged from a description of the University of Arizona's "Library As a Learning Organization" to an explanation of the University of Ohio's attempts at "Migrating a Successful Information System to the Web." Several librarians from the University of Akron offered perspectives on reference service and developments in document delivery in "Reference and Electronic Document Delivery: A Marriage Made in Heaven or Hell," and Gregory Wool of Iowa State discussed issues surrounding enhanced online records with "Bibliographic Metadata: or, We Need a Client Server Cataloging Code." Samples of the many demonstrated papers (or poster sessions) reflected a similar diversity. UC-San Diego, for instance, demonstrated a paper on computer animation; the University of Illinois at Urbana-Champaign cataloged its work in preserving and securing electronic records; and a session from Northwestern explored the relationship between building innovation and technological change. 


\section{Optimism couched with concern}

A final panel served as a wrap-up session for the weekend. This group consisted of Barbara Ford (Virginia Commonwealth University), Paul Kobulnicky (University of Connecticut), and Susan Martin (Georgetown University). Martin said that she greeted the future with a kind of "optimism couched with concern." She sensed a reassertion of the value of libraries throughout the country. People are beginning to recognize again the part that libraries have played and could play in the general culture. They expect us above all else to support privacy issues and to preserve the records of the past in whatever format available.

Ford mirrored this optimism but argued that the real common ground of libraries was more than anything else our sense of "shared values." The challenges facing libraries are certainly real enough. She noted that libraries will have to discover truly creative ways to integrate traditional print mediums with cligital sources, that we will all likely witness a great deal of restructuring, and that a lot of rethinking about out our roles and what they are all about is certainly going to be on tomorrow's agenda. But the fundamental missions of libraries will remain unaltered. Our "shared values" will, more than anything, constitute our common ground, Ford said.

\section{Wild expectations met}

If one were to look for drawbacks in the conference, the only one may have been its limited size. The Charles Hotel couldn't accommodate a larger turnout and a good number of potential participants had to be turned away. Yet the smaller number of 350 had its advantages. Interaction flourished and spirited exchanges and lively discussions followed many of the sessions. Much of the success of the conference can be attributed to the organizing genius of its cochairs: Harvard's Caroline Kent and Cheryl LaGuardia.

Harvard university librarian Richard De Gennaro summed up the overall effect and quality of the conference by conficing that it really came as something of a surprise. In toasting the weekend he admitted, "The conference succeeded beyond any of our wildest expectations."

"But then again," he added, attempting to put that surprise in perspective, "you have to remember that we had pretty wild expectations to begin with."

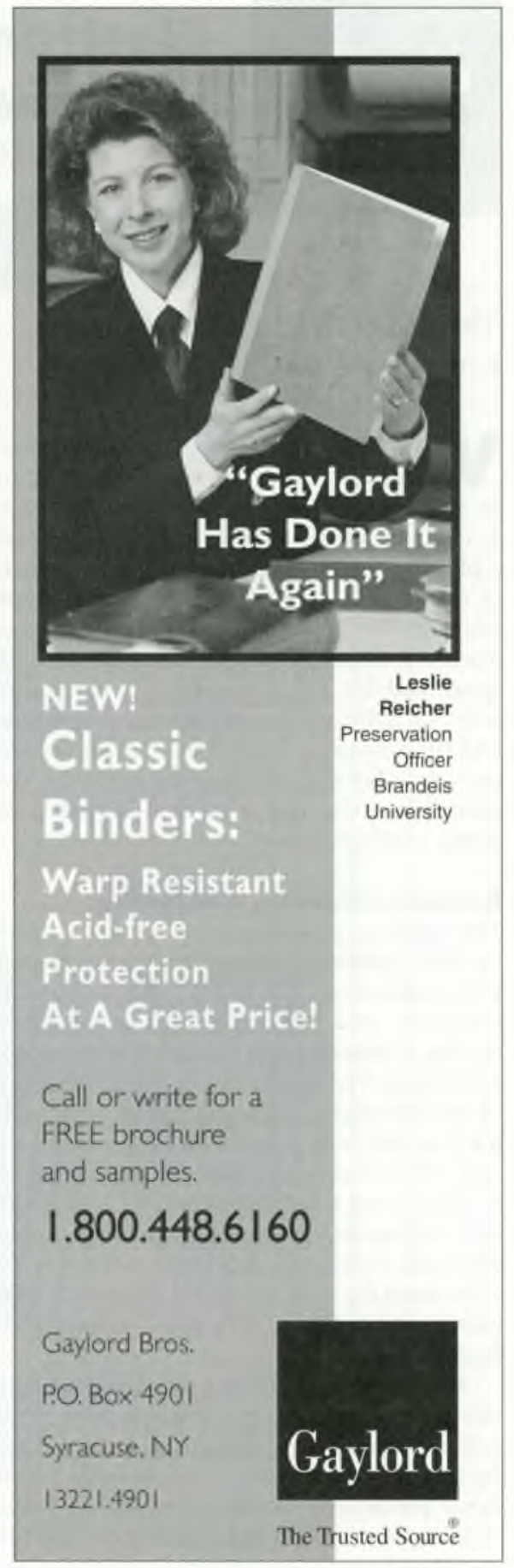

